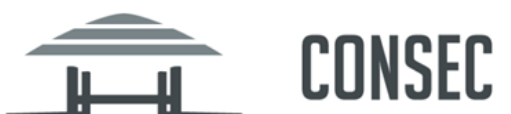
2019 9th INTERNATIONAL CONFERENCE ON CONCRETE UNDER SEVERE CONDITIONS-ENVIRONMENT \& LOADING

Unisinos University

Porto Alegre/RS - Brazil - June, 2019

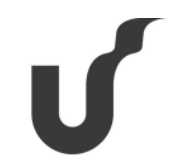

UNISINOS

\title{
Effects of elevated temperatures and of loading procedures on the bond performance of reinforcement in concrete
}

\author{
Alberto Agnoletti (1), Andrea Consiglio ${ }^{(2)}$, Giovanni Muciaccia ${ }^{(3)}$, Josipa Bosnjak ${ }^{(4)}$, Akanshu Sharma ${ }^{(5)}$ \\ (1) Department of Civil and Environmental Engineering, Politecnico di Milano, Milano, Italy, \\ alberto.agnoletti@mail.polimi.it \\ (2) Department of Civil and Environmental Engineering, Politecnico di Milano, Milano, Italy, \\ andreanino.consiglio@polimi.it \\ (3) Department of Civil and Environmental Engineering, Politecnico di Milano, Milano, Italy, \\ giovanni.muciaccia@polimi.it \\ (4) Materials testing Institute, University of Stuttgart, Stuttgart, Germany, \\ josipa.bosnjak@mpa.uni-stuttgart.de \\ (5) Institute of Construction Materials, University of Stuttgart, Stuttgart, Germany, \\ akanshu.sharma@iwb.uni-stuttgart.de
}

\begin{abstract}
The decay in the local bond performance of reinforcement bars in concrete due to exposure to high temperature is often investigated performing pull-out tests on steel rods embedded in the center of concrete specimens. The tests are generally performed in residual state i.e. upon cooling down to room temperature. However, this approach neglects not only the detrimental effects of the temperature on splitting strength of bond, but also the effects of the application of a sustained load during the heating phase, as in real applications. This paper investigates the bond performance between steel and concrete after exposure to high temperatures as a function of the rebar position, maximum exposure temperature and heating and loading sequences. Three different rebar positions are investigated, namely, rebar located in the center of the specimen (clear cover to both edges equal to $72 \mathrm{~mm}$ ), rebar at the edge (clear cover to closer edge $24 \mathrm{~mm}$ and to the other edge $72 \mathrm{~mm}$ ), rebar at the corner (clear cover to both edges $24 \mathrm{~mm}$ ). Two different heating and loading sequences are considered. In a first series, the load is applied after cooling down of the specimen from the desired target temperature, while in a second series a constant load is applied prior to temperature increase. Results obtained through the two procedures are compared and discussed, also with respect to existing code provisions.
\end{abstract}

Keywords: bond, rebar location, high temperatures, sustained loading

\section{INTRODUCTION}

It is well acknowledged that bond between steel and concrete allows load transfer from one material to the other. During such process, the internal surface of concrete in contact with the rebar is progressively damaged and this causes a relative displacement of the two materials, commonly referred to as slip. Excessive values of slip may eventually lead to collapse of the element.

Bond performance depends on a great number of parameters, namely the compressive strength and the confinement of concrete, the geometrical properties of the rebar and the anchorage length [2]. With regard to anchorage length, it is worth mentioning that it greatly affects the distribution of bond stresses. In general, bond distribution is far from uniform, reaching its maximum in correspondence of the initial portion of the bonded length and tending to zero, with a non-linear trend, while approaching the end tip. However, for small values of the ratio of bonded length to rebar diameter, the distribution of bond can safely be approximated as uniform [2].

The present work investigates the effect of temperature on steel to concrete bond properties accounting also for clear cover and anchorage length of the rebar, as additional parameters.

The clear cover, specifically, strongly influences the failure mode. In fact, in pull-out tests two failure modes are mainly observed: pull-out of the rebar and splitting of concrete. The former is induced by the progressive crushing and longitudinal cracking of the concrete keys between the ribs of the rebar, whereas the latter is due to the formation of a radial splitting crack that progressively reaches the concrete member surface, with an early and abrupt decay of bond. Pull-out failure for extraction of the rebar is observed for large values of clear cover, whereas splitting failure appears for smaller values of clear cover. In such a case, confinement offered by concrete surrounding the rebar is limited [2]. 


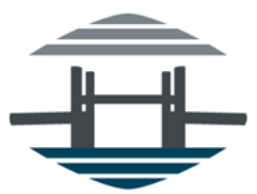

The splitting crack is induced by the radial component of the compressive stress the ribs of the rebar induce on concrete (Fig. (1)). Hoop tensile stresses arise to equilibrate the radial compressive stresses; however, as soon as the tensile resistance of concrete is exceeded, the crack is initiated and, as the load is increased, it spreads towards the surface of concrete.

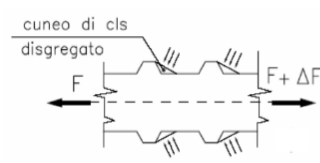

(a)

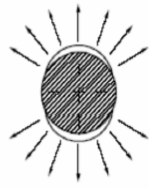

(b)

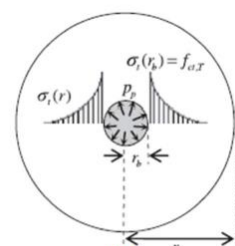

(a)

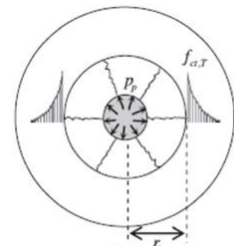

(b)

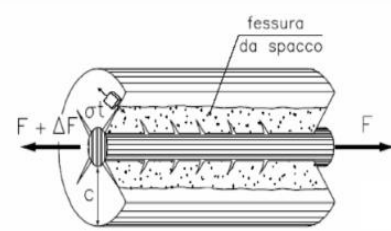

Excerpt from Gambarova and Karakoc [3]

Fig. 1: Mechanism of formation of the splitting crack

It must be noted that in case of pull-out failure (pure bond failure) of the rebar, the splitting crack still develops, even though it does not reach the concrete member surface before the collapse of the concrete keys, so that its effects are not visible.

An effective measure that inhibits splitting is the employment of transversal stirrups that take over same of the hoop stresses in concrete and contain the propagation and the opening of the radial crack. In this case the failure mode is a mixed splitting collapse since concrete does not completely detach from the rebar thanks to the confining action of transversal reinforcements [2].

While significant attention was devoted throughout the past decades to evaluate bond properties in ambient conditions, less attention was devoted to evaluating the effects of elevated temperatures, e.g. in case of fire. Additionally, the adopted experimental procedure was basically aiming to determine bond properties in residual conditions, that is after cooling down from a given target temperature [4,5], while the effects of the application of a load prior to temperature increase is generally neglected [8].

The present work aims to study the effect on bond of exposure to elevated temperatures, investigating the influence of clear cover and of loading procedures.

In such framework, it must also be noted that, for the time being, only very crude provision in existing design code related to the decay of bond due to temperature is available. For example, fib Model Code 2010 [6] recommends reducing the bond capacity of ribbed bars at elevated temperature in the same manner as it is suggested for the tensile strength of concrete. The residual bond capacity of the plain round bars is assumed to reduce by $50 \%$ and $90 \%$ for temperature of $300^{\circ} \mathrm{C}$ and $500^{\circ} \mathrm{C}$, respectively. Similar approaches can be found in other codes and guidelines [7].

\section{EXPERIMENTAL PROGRAM}

The experimental campaign was carried out in two phases: first at University of Stuttgart (DE) (detailed results are reported in Bosnjak, Sharma and Bessert, [1]) and then at Politecnico di Milano (IT). In both cases the concrete and the specimen geometry was identical, allowing a direct comparison of test results. Table 1 reports the characteristics of the mix design:

Table 1 - Concrete mix design

\begin{tabular}{cc}
\hline Components & Quantity $\left(\mathrm{kg} / \mathrm{m}^{3}\right)$ \\
\hline Water & 185 \\
Cement CEM II 32,5 R & 240 \\
Powdered limestone & 75 \\
Aggregates $(0 / 2 \mathrm{~mm})$ & 816 \\
Aggregates $(2 / 4 \mathrm{~mm})$ & 598 \\
Aggregates $(4 / 8 \mathrm{~mm})$ & 399 \\
Plasticizer & 0,25 \\
\hline
\end{tabular}




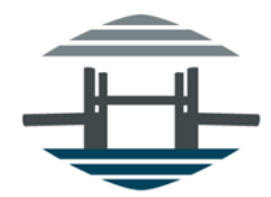

For what concerns the geometry, prismatic concrete specimens with a longitudinal rebar $(\Phi 16)$ and three transversal stirrups $(\Phi 8)$ were employed. The anchorage length is equal to 8 diameters and three different positions of the rebar in the specimens were taken into account, namely in the center, at the edge and at the corner of the specimen. Figs. (2-3) report the geometry of the specimens (all dimensions are reported in millimeters). Two stirrups were placed outside the bonded zone and one stirrup was located in the mid span of the bonded zone.

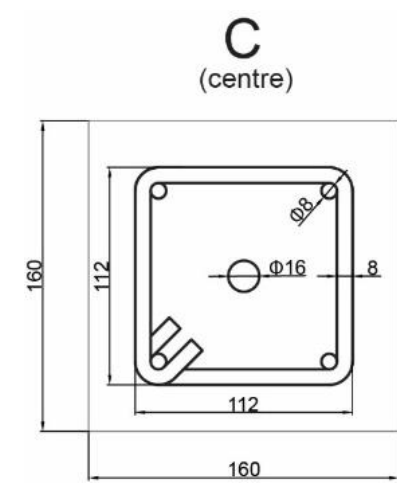

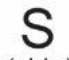

(side)

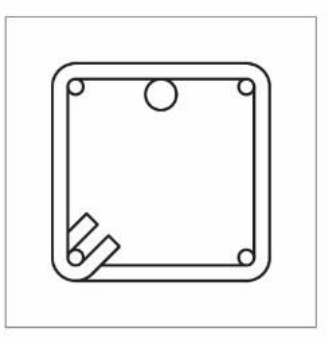

E

(edge)

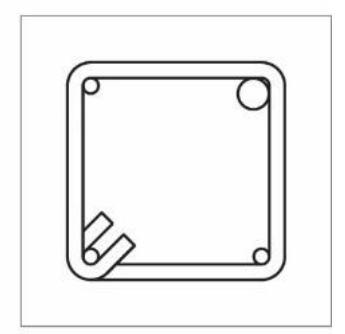

Fig. 2: Geometry of the cross-section of the specimens

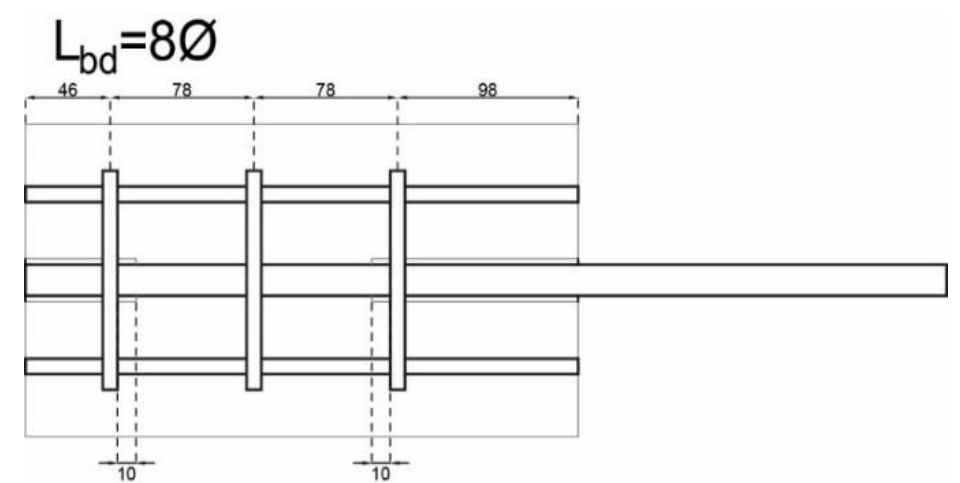

Fig. 3: Geometry of the transversal section of the specimens

As for specimens tested at Politecnico di Milano, thermocouples were installed at both tips of the bonded length, allowing to monitor the increase in temperature of the specimens during the tests performed at high temperature. Fig. (4) reports the position of the thermocouples in the specimens.

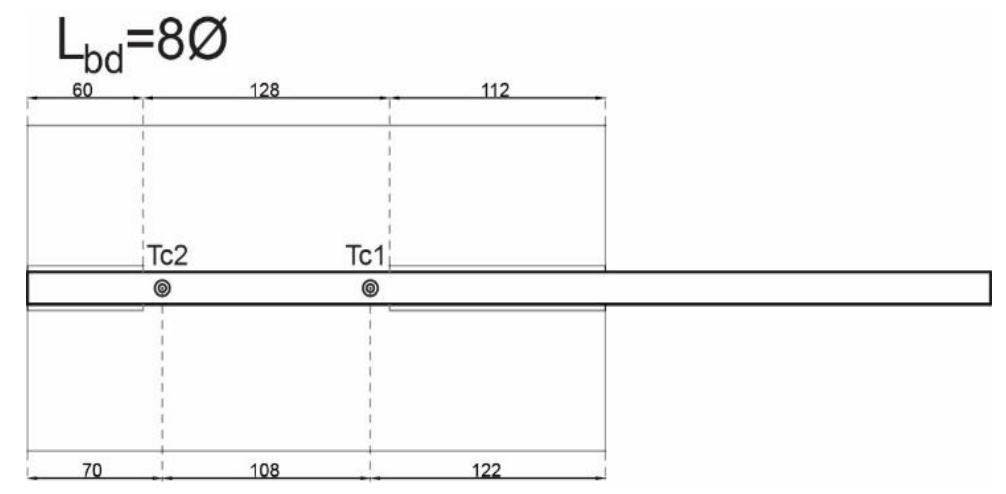

Fig. 4: Position of the thermocouples along the bonded length

Some specimens were provided with two additional thermocouples, embedded in concrete close to the external surface, to allow a more detailed monitoring of the increase of temperature during the heating phase. 

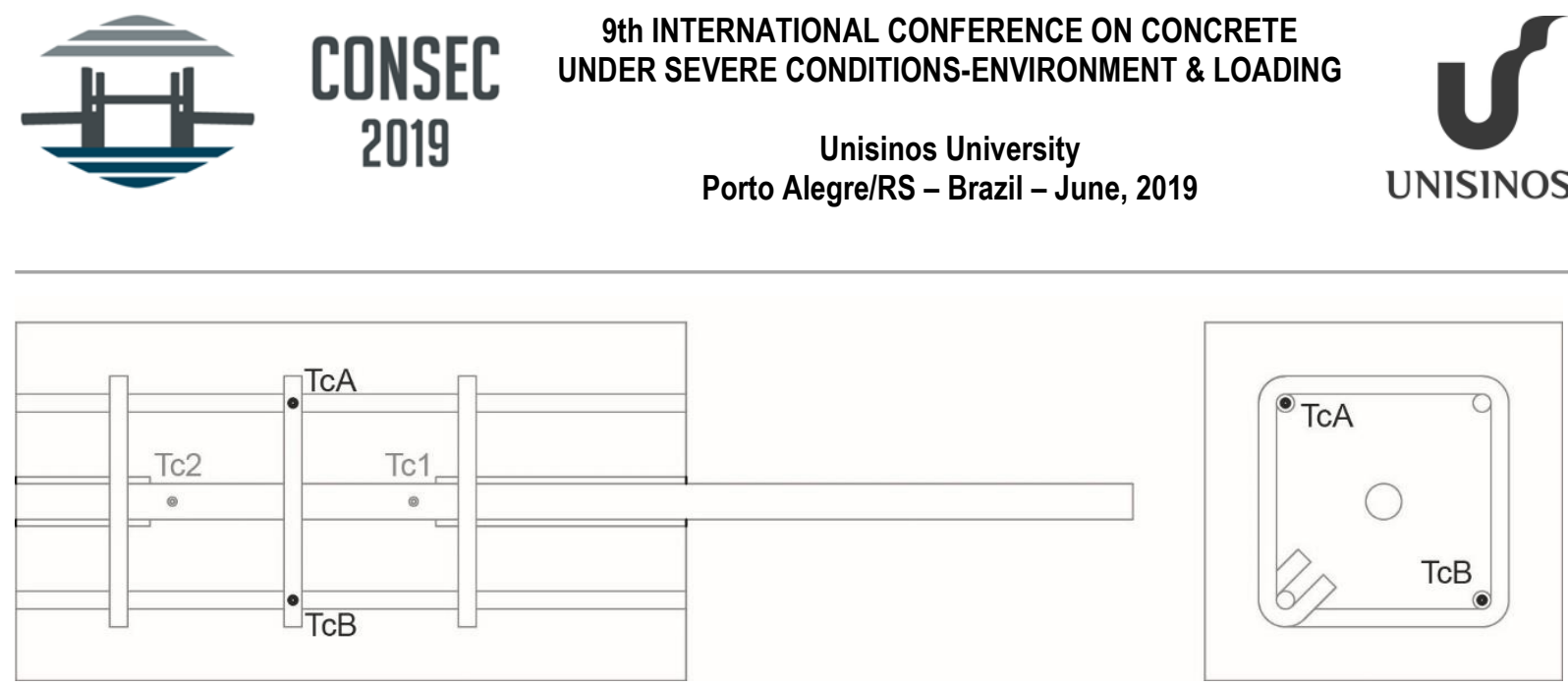

Fig. 5: Position of the extra thermo-couples in the specimens

In order to investigate the effects of heating and loading sequence, two distinct series of tests were carried out on prismatic specimens.

In the first test series (carried out at University of Stuttgart), specimens were at first exposed to a thermal cycle consisting of three steps. First, all specimens were heated to the target temperature at a rate of $2 \mathrm{C} \% \mathrm{~min}$, temperature was then maintained for 2 hours and finally the specimens were allowed to cool down at room temperature. Target temperatures and test mode are reported in Table 2 for each specimen (C-Center, S-Side and E-Edge). After cooling down, residual pull-out tests were carried out.

Table 2 - Residual pull-out tests

\begin{tabular}{ccccc}
\hline Number & Position of rebar & $\mathrm{l}_{\mathrm{a}}(\varphi)$ & Target T. $\left({ }^{\circ} \mathrm{C}\right)$ & Test mode \\
\hline 1 & $\mathrm{C}$ & 8 & 20 & Pull-Out \\
2 & $\mathrm{C}$ & 8 & 300 & Heating/Cooling + Pull-Out \\
3 & $\mathrm{C}$ & 8 & 500 & Heating/Cooling + Pull-Out \\
4 & $\mathrm{C}$ & 8 & 700 & Heating/Cooling + Pull-Out \\
5 & $\mathrm{~S}$ & 8 & 20 & Pull-Out \\
6 & $\mathrm{~S}$ & 8 & 300 & Heating/Cooling + Pull-Out \\
7 & $\mathrm{~S}$ & 8 & 500 & Heating/Cooling + Pull-Out \\
8 & $\mathrm{~S}$ & 8 & 700 & Heating/Cooling + Pull-Out \\
9 & $\mathrm{E}$ & 8 & 20 & Pull-Out \\
10 & $\mathrm{E}$ & 8 & 300 & Heating/Cooling + Pull-Out \\
11 & $\mathrm{E}$ & 8 & 500 & Heating/Cooling + Pull-Out \\
12 & $\mathrm{E}$ & 8 & 700 & Heating/Cooling + Pull-Out \\
\hline
\end{tabular}

The second test series was carried out at Politecnico di Milano. In this case, an axial load was applied on the specimen corresponding to a target percentage of the ultimate load, as reported in Table 3, which was kept constant throughout the entire test. Once the target load was attained, temperature was increased at a rate of $5^{\circ} \mathrm{C} / \mathrm{min}$. The measured temperature corresponding to pull-out of the rebar was recorded as failure temperature.

Two tests were carried out for each case, for a total of 48 tests. 


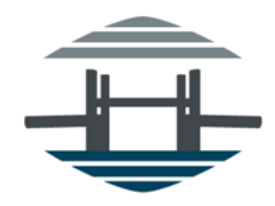

Table 4 - Constant load tests

\begin{tabular}{ccccc}
\hline Number & Position of rebar & $l_{\mathrm{a}}(\varphi)$ & Target Load (\%) & Test mode \\
\hline 1 & $\mathrm{C}$ & 8 & 100 & Pull-Out \\
2 & $\mathrm{C}$ & 8 & 80 & Constant load + Heating up to failure \\
3 & $\mathrm{C}$ & 8 & 60 & Constant load + Heating up to failure \\
4 & $\mathrm{C}$ & 8 & 40 & Constant load + Heating up to failure \\
5 & $\mathrm{~S}$ & 8 & 100 & Pull-Out \\
6 & $\mathrm{~S}$ & 8 & 80 & Constant load + Heating up to failure \\
7 & $\mathrm{~S}$ & 8 & 60 & Constant load + Heating up to failure \\
8 & $\mathrm{~S}$ & 8 & 40 & Constant load + Heating up to failure \\
9 & $\mathrm{E}$ & 8 & 100 & Pull-Out \\
10 & $\mathrm{E}$ & 8 & 80 & Constant load + Heating up to failure \\
11 & $\mathrm{E}$ & 8 & 60 & Constant load + Heating up to failure \\
12 & $\mathrm{E}$ & 8 & 40 & Constant load + Heating up to failure \\
\hline
\end{tabular}

\section{EXPERIMENTAL RESULTS}

Test results for both residual and constant load test series are reported in Table 5 and 6 , respectively, as well as in Fig. (6) and (7). The bond strength $\tau$ is computed assuming, given the short anchorage length, a uniformly distributed bond stress acting along the rebar.

Table 5 - Results of residual pull-out tests

\begin{tabular}{cccccc}
\hline Number & Position of rebar & $\mathrm{la}_{\mathrm{a}}(\varphi)$ & Target T. $\left({ }^{\circ} \mathrm{C}\right)$ & $\tau_{\mathrm{m}}(\mathrm{MPa})$ & Failure mode \\
\hline 1 & $\mathrm{C}$ & 8 & 20 & 14,1 & Pull-Out \\
2 & $\mathrm{C}$ & 8 & 300 & 12,3 & Pull-Out \\
3 & $\mathrm{C}$ & 8 & 500 & 7,1 & Pull-Out \\
4 & $\mathrm{C}$ & 8 & 700 & 3,8 & Pull-Out \\
5 & $\mathrm{~S}$ & 8 & 20 & 10,6 & Pull-Out \\
6 & $\mathrm{~S}$ & 8 & 300 & 9,3 & Splitting \\
7 & $\mathrm{~S}$ & 8 & 500 & 5,0 & Splitting \\
8 & $\mathrm{~S}$ & 8 & 700 & 1,9 & Splitting \\
9 & $\mathrm{E}$ & 8 & 20 & 7,4 & Splitting \\
10 & $\mathrm{E}$ & 8 & 300 & 5,4 & Splitting \\
11 & $\mathrm{E}$ & 8 & 500 & 4,3 & Splitting \\
12 & $\mathrm{E}$ & 8 & 700 & 1,8 & Splitting \\
\hline
\end{tabular}

Table 6 - Results of constant load tests

\begin{tabular}{|c|c|c|c|c|c|c|c|}
\hline Number & $\begin{array}{c}\text { Position of } \\
\text { rebar }\end{array}$ & $l_{a}(\Phi)$ & $\tau_{\mathrm{b}}(\mathrm{MPa})$-Test 1 & T. $\left({ }^{\circ} \mathrm{C}\right)$-Test 1 & $\tau_{\mathrm{b}}(\mathrm{MPa})$-Test 2 & T. $\left({ }^{\circ} \mathrm{C}\right)$-Test 2 & $\begin{array}{c}\text { Failure } \\
\text { mode }\end{array}$ \\
\hline 1 & $\mathrm{C}$ & 8 & 13,2 & 30 & 12,5 & 30 & Pull-Out \\
\hline 2 & $\mathrm{C}$ & 8 & 9,0 & 47,2 & 9,0 & 63,2 & Pull-Out \\
\hline 3 & $\mathrm{C}$ & 8 & 7,0 & 111,8 & 7,1 & 108,7 & Pull-Out \\
\hline 4 & $\mathrm{C}$ & 8 & 5,2 & 523,1 & 5,2 & 511,8 & Pull-Out \\
\hline 5 & $\mathrm{~S}$ & 8 & 7,5 & 30 & 8,1 & 30 & Pull-Out \\
\hline 6 & $\mathrm{~S}$ & 8 & 6,3 & 71,2 & 6,4 & 60,2 & Splitting \\
\hline 7 & $\mathrm{~S}$ & 8 & 4,3 & 432,4 & 4,4 & 465,3 & Splitting \\
\hline 8 & $\mathrm{~S}$ & 8 & 3,1 & 529,2 & 3,1 & 529,3 & Splitting \\
\hline 9 & $\mathrm{E}$ & 8 & 7,3 & 30 & 8,7 & 30 & Splitting \\
\hline 10 & $\mathrm{E}$ & 8 & 6,5 & 117,4 & 6,4 & 75,3 & Splitting \\
\hline 11 & E & 8 & 4,4 & 519,9 & 4,8 & 477,3 & Splitting \\
\hline 12 & $\mathrm{E}$ & 8 & 3,2 & 512,3 & 3,2 & 501,0 & Splitting \\
\hline
\end{tabular}



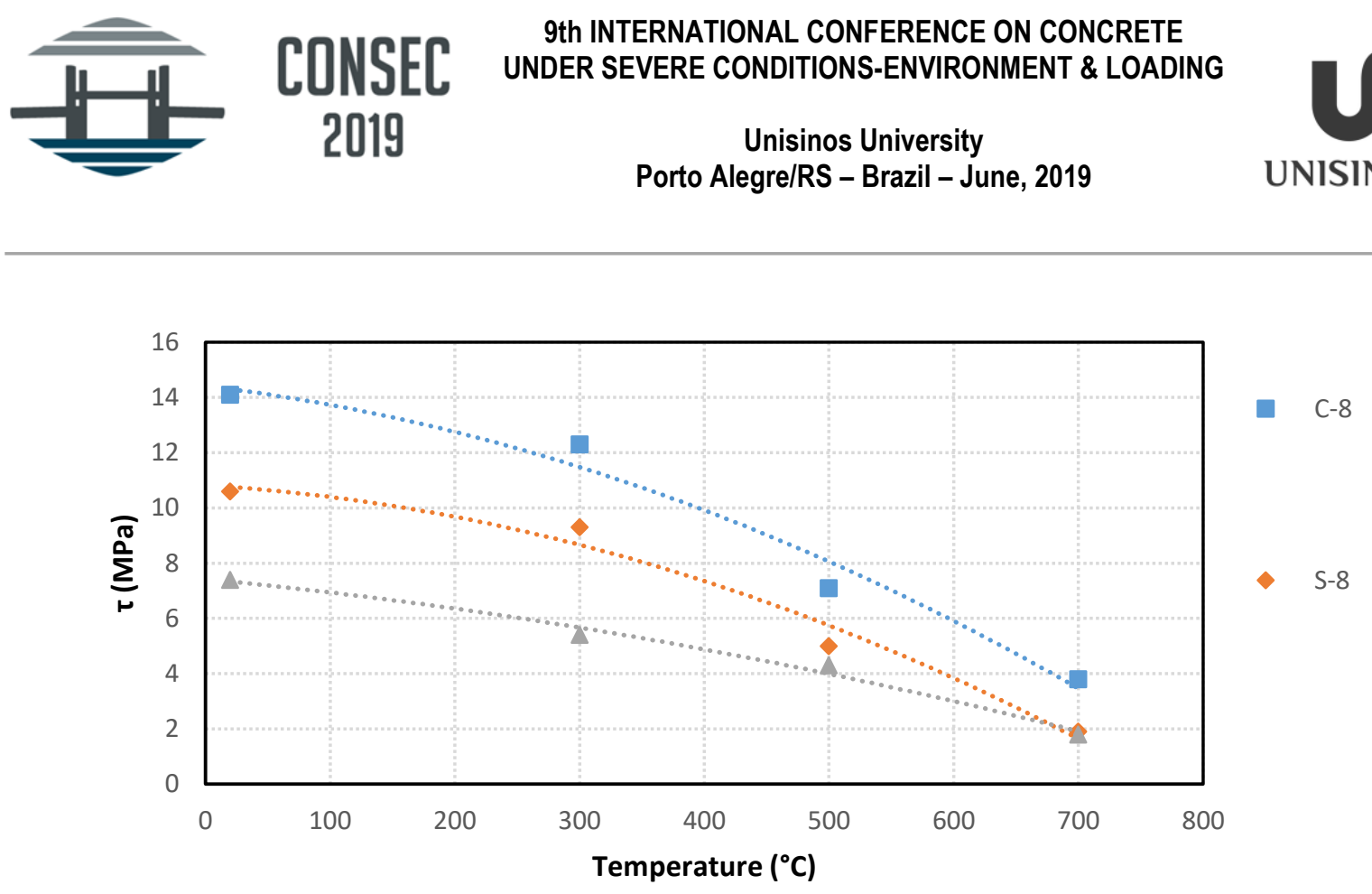

Fig. 6: Results of residual pull-out tests

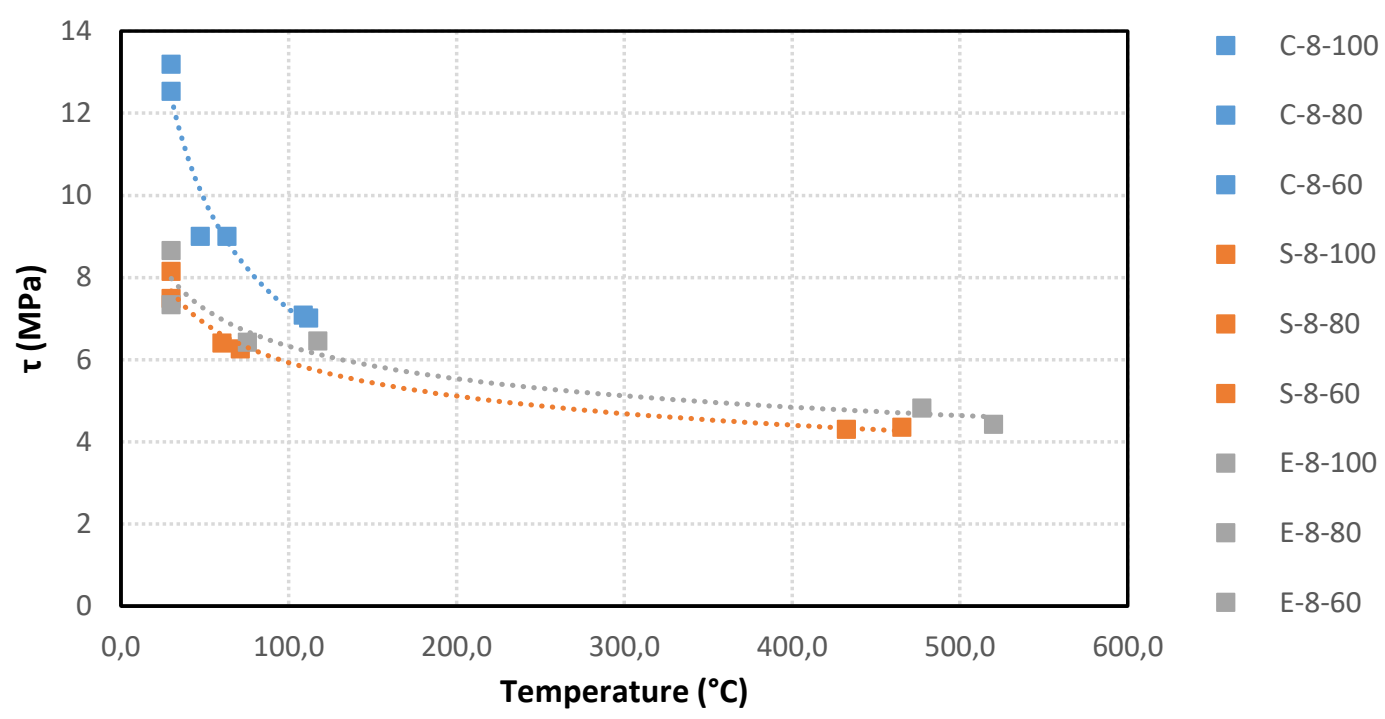

Fig. 7: Results of constant load tests

Additionally, Figs. (8) and (9) report, for both testing procedure, test results normalized with respect to the bond strength recorded at room temperature for each of the three positions of the rebar in the specimen.

For both residual and constant load test series, a clear decay of bond strength as a function of temperature increase is detected. The trend reported by residual tests is similar to previous studies [5], with no evident dependency of the bond decay on the value of clear cover (Fig. 8). 

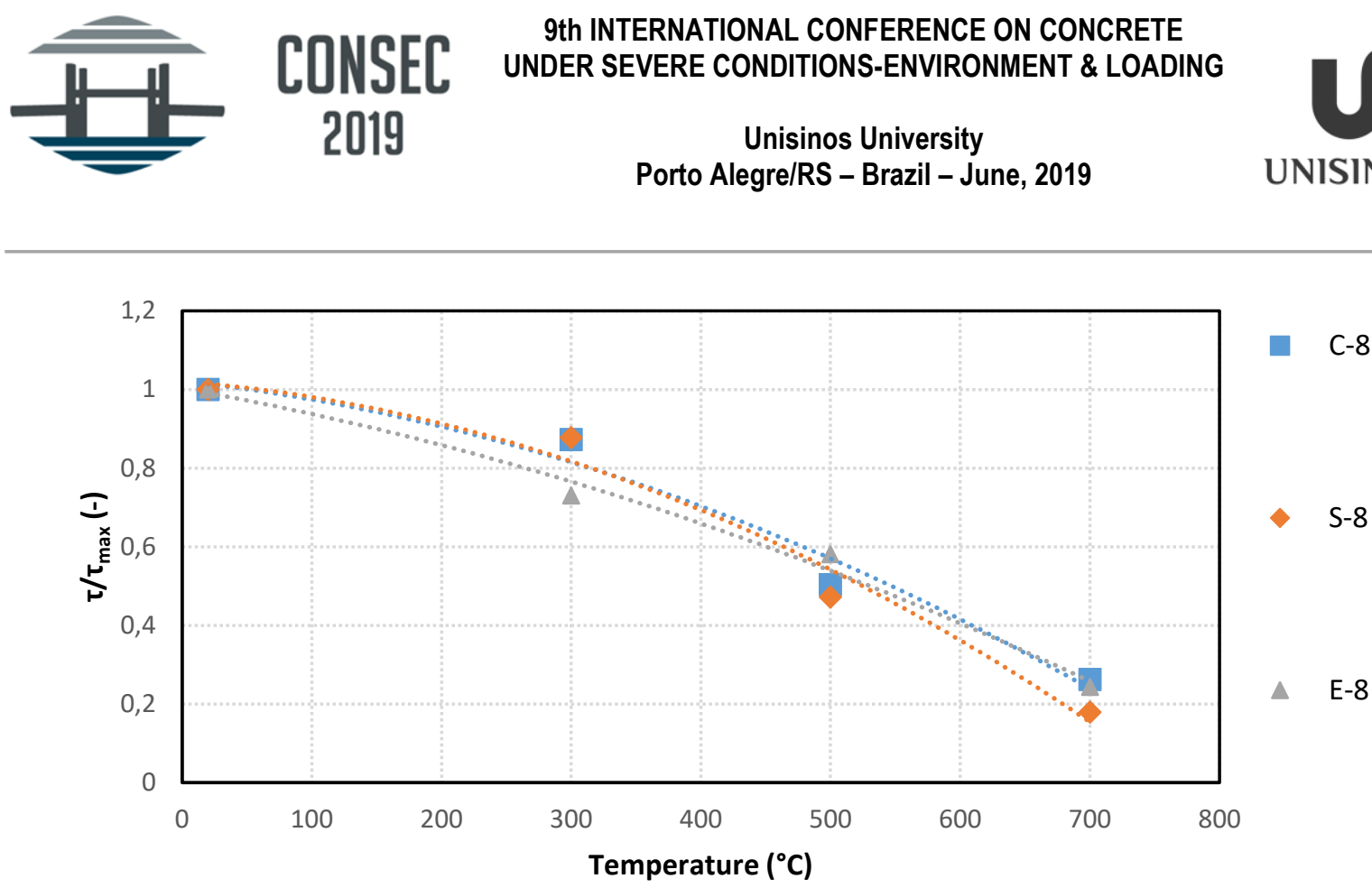

Fig. 8: Normalized results of residual pull-out tests

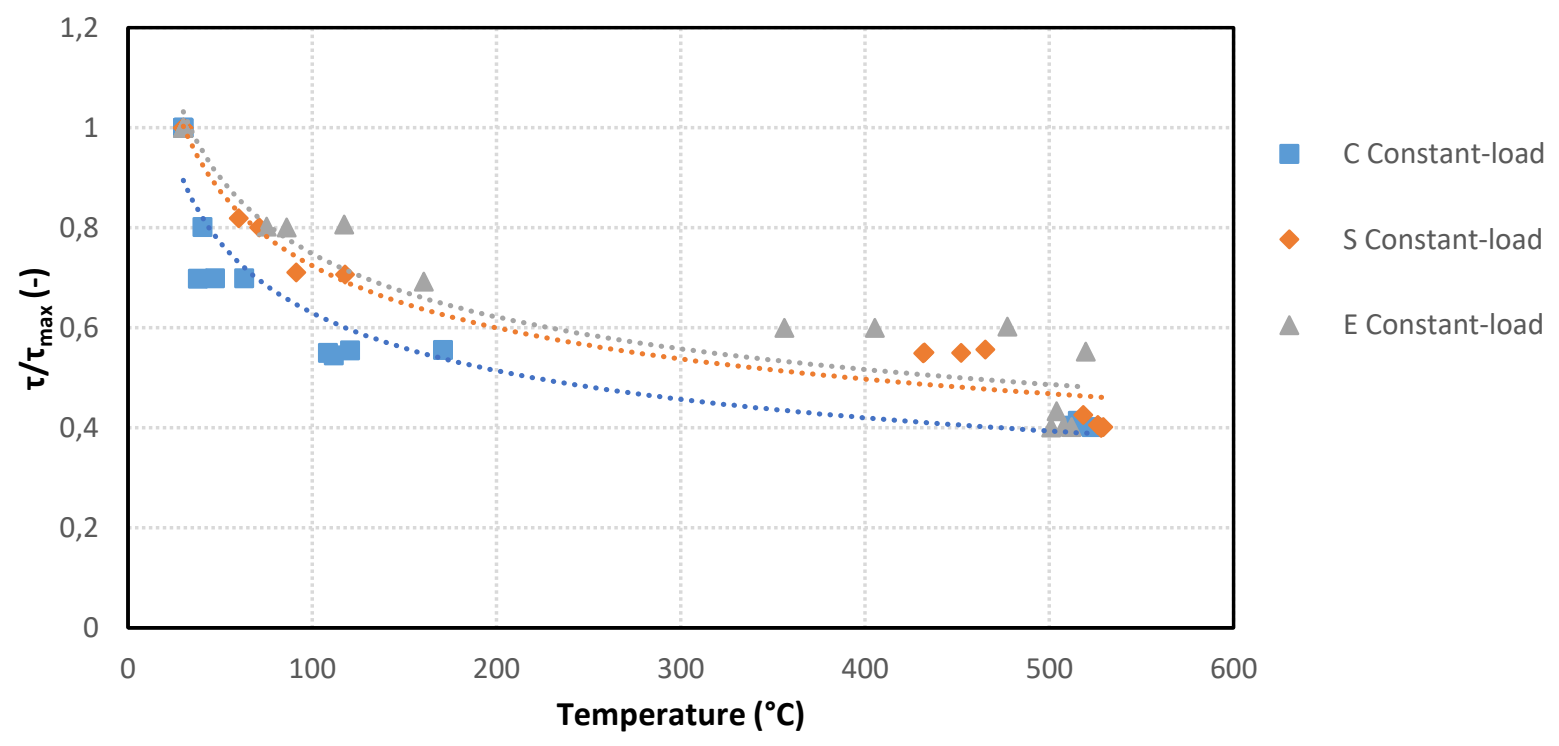

Fig. 9: Normalized results of the constant load tests

From the results of constant load tests (Fig. 9) a decay of bond strength as function of temperature is observed as well. However, in this case a dependency of the decay of bond on the clear cover is present. The larger the clear cover, the more pronounced the decay.

Fig. 10 finally compares results of residual and constant-load test series. 

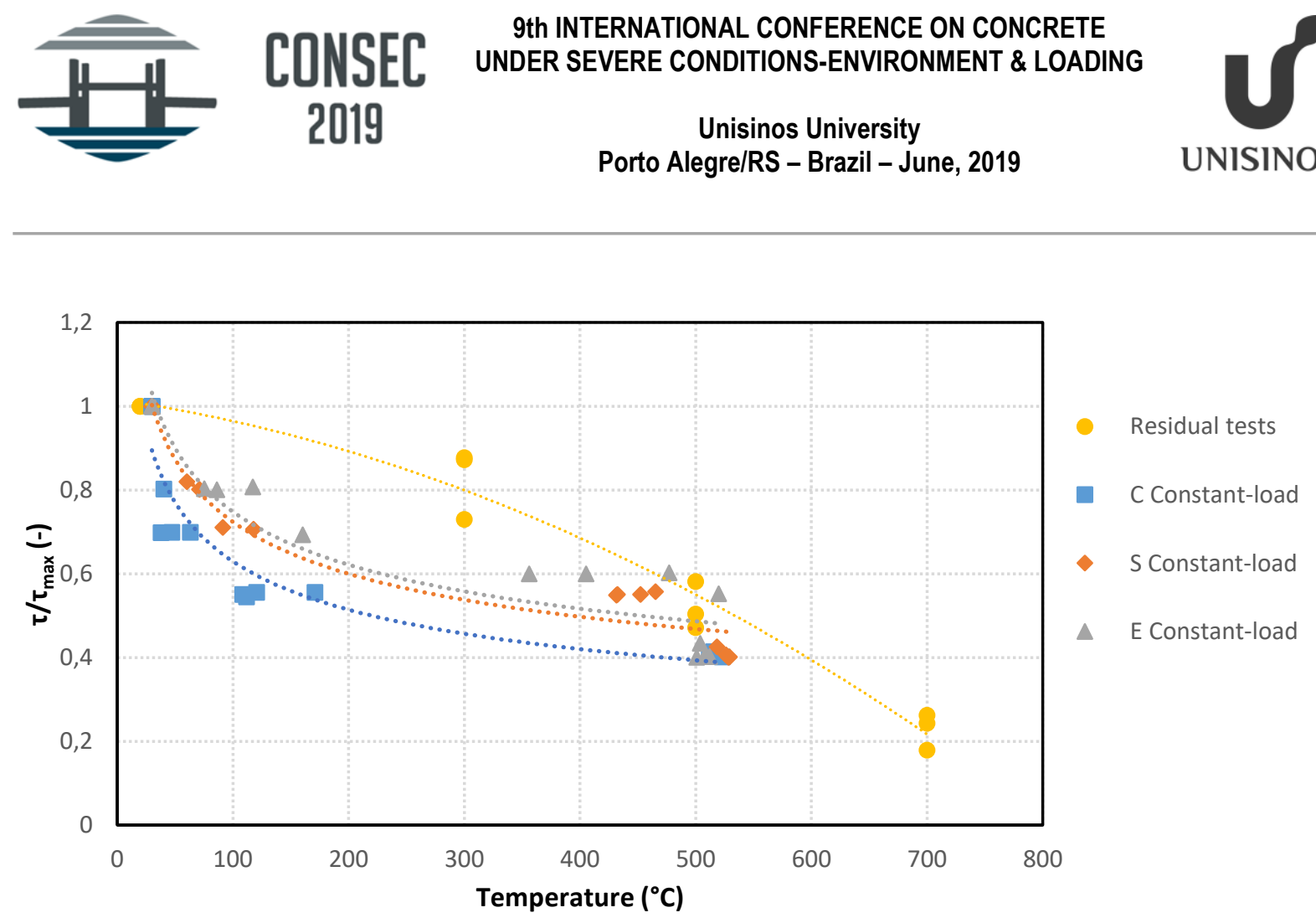

Fig. 10: Comparison of the results obtained by different heating and loading sequences

Even though the geometry and the composition of the specimens coincide, it is clear that the decay of bond strength is more pronounced in the case of constant-load tests. It can be assumed that the phenomenon is to be appointed to the presence of a constant load during the heating phase. More specifically, what seems to be playing a major role is causing such detrimental effects on the response of bond to high temperature is creep.

Constant load tests could better represent the state of a structure during an exceptional event as fire: a strong increase in temperature is observed while a constant load is applied to structure (eg: self-weight). It must be noted that for all parts of the structure that are subjected to high load levels, such as in beam to column connection, even a moderate temperature increase (up to $100^{\circ} \mathrm{C}$, as reported in Fig. 10) could lead to the collapse of the connection. Additionally, in case of fire, the heating rate would be much higher than the one achieved in the present investigation, with an even more pronounced decay of bond strength.

On the other hand, residual tests are more representative of the behavior of a structure after a fire event, when the assessment of safety is crucial for the possible reuse of the building.

It must be noted that, the results provided by the two approaches coincide for load levels lower than $50 \%$ of the capacity at cold state, that is when the effects of creep are negligible.

\section{CONCLUSIONS}

The decay of bond strength as a function of temperature, bar position and heating/loading sequence was experimentally investigated. The following conclusions can be drawn:

- Bond strength decays as the temperature increases.

- When measuring residual properties, namely when the heating phase precedes the loading phase, bond decay is independent from the clear cover, while a dependency is detected when loading and heating phase are simultaneous, with a more pronounced decay for higher values of clear cover.

- Bond decay is more evident in constant load procedure, probably due to the detrimental effect of creep. However, for low load values, results obtained through the two procedures basically coincide. 


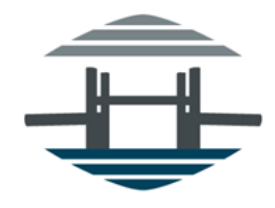

\section{REFERENCES}

[1] Bosnjak, J., Sharma, A., Bessert, S., "Bond performance of reinforcement in concrete after exposure to elevated temperatures". In: Sharma, A., Hofmann, J. (ed.), Institute of Construction Materials University of Stuttgart, "Proceedings of the 3rd International Symposium on Connections between Steel and Concrete", Stuttgart Germany September 2017, IWB, Stoccarda, pp. 850-861, 2017.

[2] fib Bulletin 10 , "Bond of reinforcement in concrete". Fédération internationale du béton (fib), Lausanne, Switzerland, 2000.

[3] Gambarova, P.G. and Karacoç C., "Shear-confinement interaction at the bar-to-concrete interface". In: "Bond in Concrete", Edited by P. Bartos, Applied Science, London, pp. 82-95, 1982.

[4] Lubloy, E. and Balazs, G., "Temperature effects on bond between concrete and reinforcing steel". "Journal of Faculty of Civil Engineering", 26, pp. 27-35, 2014.

[5] Lubloy, E., Hlavicka, V., "Bond after fire”. Construction and Building Materials, 132, pp. 210-218, 2017.

[6] MC2010, "Model Code for Concrete Structures", International federation for concrete, Fédération internationale du béton (fib), Lausanne, Switzerland, 2012.

[7] EN 1992 Part 1-1, "Eurocode 2: Design of concrete structures: General rules and rules for buildings". European Committee for Standardization, Brussels, 2004.

[8] Muciaccia, G., Consiglio, A., Rosati, G., "Recent developments in design of post-installed rebar connections under temperature". In: Sharma, A., Hofmann, J. (ed.), Institute of Construction Materials University of Stuttgart, "Proceedings of the 3rd International Symposium on Connections between Steel and Concrete”, Stuttgart Germany September 2017, IWB, Stoccarda,, pp. 1100-1109, 2017. 